\title{
Música e cosmologia em Filolau de Crotona
}

\author{
GUILHERME MAGALHÃES OLIVEIRA \\ FASCS (guimoliveira@gmail.com)
}

\section{Os princípios cosmológicos de Filolau de Crotona}

\author{
"We are all Pythagoreans" \\ Iannis Xenakis (1992, p. 202)
}

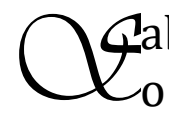

abemos muito pouco sobre a vida de Filolau de Crotona, o primeiro dos pensadores pitagóricos que nos deixou alguns escritos, e podemos dizer que a história do pitagorismo começa com seus fragmentos. Não podemos afirmar com certeza a data de seu nascimento mas, provavelmente, Filolau nasceu em 470 a.C., e foi contemporâneo de Sócrates, tendo vivido, aproximadamente, até 385 a.C.. Segundo recolhimento de Diógenes Laércio, Filolau escreveu um livro intitulado $D a$ natureza das coisas (peri physeos), que Platão teria comprado de seus parentes quando visitou a Sicilia e o teria influenciado no diálogo Timeu. 0 pouco que sabemos sobre este livro chegou até nós por meio de fragmentos doxográficos e parece que começava assim (fr.1):

A natureza na ordem do mundo foi unida harmoniosamente a partir de coisas ilimitadas e também de coisas limitantes, a ordem do mundo como um todo e todas as coisas nele. (Diógenes Laércio, VIII, 85. In: KAHN, 2007, p. 42)

Em primeiro lugar, devemos compreender o significado de "coisas ilimitadas" e "coisas limitantes", portanto o significado de ilimitado (apeiron), e limite (peras), já que o cosmos é formado a partir destes dois princípios. Em segundo lugar, analisaremos o significado de harmonia como terceiro princípio, que pressupõe união e proporção dos dois primeiros. Depois, enfrentaremos sua relação com o número (arithmos).

Ao realizarmos qualquer tipo de investigação sobre a formação do cosmos, aqui entendido como um todo ordenado, o primeiro problema a enfrentar é o limite da linguagem para tratar desses assuntos. Como explicar em palavras algo que aconteceu "antes" de existir o tempo? Como nosso logos 
(argumentação e palavra) é limitado e tem um movimento obrigatório de medida (a proposição e sua temporalidade), tem-se que lidar desse modo quanto ao cosmos e a geração das coisas. 0 cosmos não foi formado por sucessões temporais, não existe antes e depois quando o assunto é cosmologia no âmbito da especulação filosófica pré-socrática. 0 cosmos se formou de uma só vez, fora do tempo e do espaço, até porque só há tempo e espaço se há cosmos formado. Portanto, sempre que usarmos as palavras: "primeiro", "segundo", "antes" ou "depois", não significa que os acontecimentos se deram nesta ordem, mas que nossa reflexão e nossa linguagem precisam destas palavras por estarmos pensando dentro da noção de tempo e espaço.

Peras significa "fim", "limite", "fronteira", "aquilo que limita ou tem limite". Já apeiron significa "ilimitado", "sem fronteira", "infinito", "incontável", "inumerável", "indefinido". Está mais do que claro que Filolau está trabalhando com princípios (archai) opostos, ou seja, o limitado ou "aquilo que limita", e o ilimitado, que não têm medida, é indefinido. Estes dois princípios se encontram de alguma forma "combinados" no cosmos, em todas as coisas que são cosmicamente geradas.

Em um primeiro momento, somos levados a pensar que Filolau está se referindo ao limitado e ao ilimitado como noções separadas, mas é de fundamental importância notar que ele usa o plural ao invés do singular no fr.1: fala de "coisas" que possuem "naturalmente" o limitado e, por outro lado, de "coisas" que possuem em sua natureza o ilimitado, sugerindo que o cosmos não foi formado "a partir" do limite e do ilimitado entendidos em si mesmos, mas que tudo o que é gerado e faz o cosmos já é ilimitado e limitante. Por outro lado, o uso da palavra "coisas" (ta eonta) pode sugerir que se fala de singularidades, istos, o que é o caso aqui, se essas singularidades tiverem como princípios o limitado e o ilimitado para serem como tal, ou seja, coisas determinadas no todo ordenado. Quando tratarmos dos princípios formadores, utilizaremos o singular: limitado e ilimitado. Já as "coisas" possuem, ou contêm, limitado e ilimitado, e são limitantes e ilimitadas.

Não podemos esquecer que tudo no cosmos possui ambos os princípios, por exemplo, em nível elementar, as 
formas e os contornos de uma flor nos dão uma ideia de limite; por outro lado, o ar ao nosso redor dá uma ideia de ilimitado porque não possui uma forma definida; o corpo humano, já que possui forma, limita e, ao mesmo tempo, é ilimitado se pensado em suas transformações ao longo de sua existência.

Ainda sobre limitado e ilimitado, Aristóteles, segundo Estobeu, recolhido de um possível tratado que teria escrito sobre a filosofia pitagórica que infelizmente se perdeu, nos dá alguns exemplos de "coisas" que se apresentam com características mais ilimitadas do que limitantes: "No primeiro livro da sua obra Sobre a filosofia de Pitágoras escreve ele que o universo é uno e que do ilimitado nele são introduzidos o tempo, o sopro e o vazio, que distingue sempre os lugares de cada uma das coisas" (Estobeu, Anth. I, 18, 1c. In: KIRK; RAVEN; SCHOFIELD, 2008, p. 358). Aristóteles associa o tempo, o "sopro" ou ar, e o vazio, com o ilimitado porque eles não possuem topos. Por outro lado, não podemos confundir tempo,

252 ar e vazio, com o próprio ilimitado que é princípio formador do cosmos junto com o limitado. Aristóteles, ao referir-se ao tempo ilimitado, ao ar ilimitado e ao vazio ilimitado, não está dando nomes ao ilimitado formador do cosmos (HUFFMAN, 2006, p. 43-44). ${ }^{1}$ Poderíamos supor, no máximo, que estes seriam as "primeiras" coisas formadas que se "aproximam" em maior grau do ilimitado. Sobre o ilimitado, como princípio cosmológico, não podemos dizer nada, apenas recolher ou reconhecer na natureza aquilo que apresenta uma "tendência" maior para o ilimitado. Isto se dá porque o princípio é poder primeiro e não há nada anterior a ele, já que tudo o que é definido e explicado tem sua origem desta arche.

Outra questão que sobressai é que o tempo em si mesmo, ou seja, o tempo em sua essência é algo completamente diferente da divisão cronológica que fazemos quando o dividimos em anos, meses e dias. 0 tempo ilimitado ao qual

${ }^{1}$ Huffman afirma que os princípios são limitantes e ilimitados (plural) e não aceita a ideia de limite e ilimitado (singular) porque, para esse intérprete, seria platonizar Filolau. Além disso, ele propõe enumerar alguns ilimitados, o que não achamos que seja possível já que tudo contêm limitado e ilimitado combinados. 
Aristóteles se refere é continuum. 0 mesmo ocorre com o ar e o vazio uma vez que estes, como continuum, também não podem ser medidos nem contados. Mas, ao pensá-los na natureza, portanto interagindo com outras coisas, reconhecemos limites no tempo, no ar e no vazio. Isto ocorre porque, apesar de algumas coisas tenderem para o ilimitado, tudo no cosmos necessariamente também apresenta características limitantes. Quando dividimos o tempo em anos, meses e dias não o fazemos arbitrariamente. Ao observarmos a natureza, reconhecemos que há medida, por isso dividimos o tempo em partes, como o fazemos (pelas marés, equinócios, solstícios, etc). O tempo, ar e vazio poderiam ser quantificáveis, mas sempre pensamos neles interagindo com outras coisas e não em si mesmos. Reconhecemos seções de vazio pela inserção de corpos. O tempo, quando o dividido em partes, e o ar que atravessa o tubo de uma flauta, também são divididos ao fecharmos seus registros gerando notas diferentes.

Entretanto, o fr. 1 afirma que o cosmos não pode ser formado só com o limitado ou só com o ilimitado, mas que estes princípios foram unidos harmoniosamente, ou seja, foram combinados de modo a criar uma harmonia. A palavra harmonia significa "meios de união", "ajuste", "estrutura", "acordo", "princípio de união". Como limitado e ilimitado são princípios opostos ou dessemelhantes, um terceiro se faz necessário para bem uni-los: a harmonia. A segunda parte do fr. 6 reafirma o papel da harmonia como princípio de união entre opostos).

Como esses princípios não eram semelhantes, nem do mesmo tipo, teria sido impossível combiná-los harmoniosamente se a harmonia não tivesse intervindo entretanto, foi isso o que ocorreu. Não são as coisas que são semelhantes e do mesmo tipo que precisam de harmonia, mas coisas dessemelhantes, diferentes e de velocidades desiguais; tais coisas devem ser combinadas pela harmonia, se serão mantidas unidas em um cosmos. (Estobeu, Anth. I, 21, 7d. In: BURKERT, 1972, p. 251-2).

É através da harmonia que limitado e ilimitado são concordantes e expressam o próprio modo de ser do cosmos. A harmonia em Filolau tem a mesma função para Empédocles e Heráclito, ou seja, produzir unidade a partir da multiplicidade, 
sendo que a grande diferença de Filolau será como ele irá desenvolvê-la a partir de razões numéricas e escalas musicais (KAHN, 2007, p. 42-43).

Filolau não se refere a uma harmonia qualquer. No Fr. 6a, que apresentaremos mais adiante, ele dá mais algumas pistas sobre limitado e ilimitado, e de como há um ajuste harmônico entre opostos. 0 fragmento apresenta as razões numéricas que serão usadas para gerar uma harmonia específica, ou seja, uma estrutura matemática que dá origem à escala musical diatônica.

Em se tratando de sons, podemos pensá-los como fizemos com o tempo, o ar e o vazio, e percebemos que eles também são continuum. 0 som, pensado em si mesmo, possui uma infinidade de alturas, mas para obtermos uma nota específica, um dó, por exemplo, temos que definir uma determinada altura que só é alcançada por meio de cálculos matemáticos. Neste contexto, um continuum indefinido quanto 254 às possibilidades de alturas possui características ilimitadas, enquanto que a delimitação estabelecida nesse continuum, que resulta numa nota ou altura específica, apresenta características limitadas.

Ao observarmos, por exemplo, a corda de um violino, nos damos conta das inúmeras possibilidades de alturas que ela contém potencialmente, o que nos remete a características ilimitadas. Por outro lado, quando um violinista escolhe determinada posição para essa corda e a pressiona emitindo uma altura ou nota específica (portanto, dividindo a corda segundo uma proporção), ele está impondo um limite às inúmeras possibilidades de alturas. 0 limitado, no caso, é a posição escolhida pelo violinista ao pressionar a corda, mas, no contexto específico do pensamento musical grego, não basta escolher qualquer apanhado de alturas para ter uma ordem musical: esta deve seguir uma proporção específica, uma harmonia capaz de estabelecer limite ao ilimitado seguindo uma estrutura baseada no número (arithmos). Desta forma, percebemos que harmonia e arithmos estão intimamente ligados e parece-nos difícil definir um sem se remeter ao outro. o que difere uma harmonia qualquer de uma harmonia específica, no caso de Filolau, é que a harmonia utilizada para 
formar o cosmos, através da combinação harmoniosa entre limitado e ilimitado, possui número (arithmos). Ou seja, o cosmos foi formado a partir de uma estrutura baseada em proporções específicas que correspondem aos intervalos musicais, sendo a música uma imagem ou imitação dessa estrutura encontrada na Natureza, um microcosmos. Segundo Kahn, em Filolau, "a harmonia é numérica na forma" (KAHN, 2007, p. 44).

\section{Arithmos}

Arithmos significa "número", "cálculo", "soma", "quantidade", "ritmo". Quando Filolau usa a palavra número, não devemos entendê-la como número matemático, mas no sentido de que o número, que está diretamente ligado à harmonia que concilia o limitado e o ilimitado, pressupõe ritmo medido, periodicidade.

Número é ritmo com proporção, periodicidade de um fluxo contínuo medido. Para esclarecer esta questão pensemos novamente no tempo. Quando observamos o movimento dos astros e percebemos que a Terra deu uma volta completa ao redor do Sol, chamamos isto de um ano, o que significa que reconhecemos na natureza um ciclo, uma ordem, uma medida no fluxo incessante e, ao perceber este ciclo, nomeado um ano, estamos criando tempo no fluxo, medida no movimento. No decorrer de um ano, há mudanças na natureza e estas apresentam características distintas, quatro vezes neste período, que nomeamos estações. No fluxo da natureza observamos ritmo e medida, portanto arithmos. Por isso o número deve ser entendido como indicador de periodicidade ou ciclo como medida, e mais uma vez a música serve para ilustrar nossa argumentação. Como a música é arte com medida, os sons precisam ter um fluxo medido, devem soar por um determinado período. O fluxo participa do ilimitado, enquanto um tempo determinado de um som participa do limitado, já a proporção matemática que rege o tempo das notas é uma harmonia baseada no número. Assim, construímos um microcosmo musical que, por ser natureza, segue as mesmas leis do macrocosmo. 
O número assume um papel fundamental em Filolau, como podemos constatar no fr. 4:

E de fato todas as coisas conhecidas têm número, pois nada pode ser pensado ou conhecido sem número. (Estobeu, Anth. I, 21, 7b. In: KIRK; RAVEN; SCHOFIELD, 2008, p. 344) ${ }^{2}$

Filolau afirma que tudo o que podemos conhecer tem número e nada pode ser pensado ou conhecido sem arithmos. É de fundamental importância notar que o número aparece num contexto epistemológico neste fragmento, mas isto não diminui sua importância para a cosmologia de Filolau, como sugere Huffman ao afirmar que é "notável que 'número' seja utilizado somente num contexto epistemológico e nunca num contexto cosmológico nos fragmentos de Filolau que sobreviveram" (HUFFMAN, 2006, p. 173).

Ao analisarmos o que Aristóteles legou sobre os pitagóricos na Metafísica, e confrontarmos essas informações com os fragmentos de Filolau recolhidos por outros doxógrafos, uma série de problemas sobre o papel do número coloca-se diante de nós. Todo o problema começa quando Aristóteles, na Metafísica, afirma que o princípio de toda filosofia pitagórica é o número:

Os assim chamados pitagóricos são contemporâneos e até mesmo anteriores a esses filósofos. Eles por primeiro se aplicaram às matemáticas, fazendo-as progredir e, nutridos por elas, acreditaram que os princípios delas eram os princípios de todos os seres. E dado que nas matemáticas os números são, por sua natureza, os primeiros princípios, e dado que justamente nos números, mais do que no fogo e na terra e na água, eles achavam que viam muitas semelhanças com as coisas que são e que se geram (...). (Met. A 5, 985b23)

0 grande problema é a afirmação de Aristóteles que, para os pitagóricos, o número é o primeiro princípio. Ao confrontar esta afirmação com o que analisamos até agora nos fragmentos de Filolau, cabe a seguinte pergunta: se o princípio de toda a filosofia pitagórica é o número, como diz Aristóteles,

\footnotetext{
${ }^{2}$ Algumas alterações foram feitas na tradução portuguesa levando em conta a tradução da edição inglesa.
} 
por que este não afirma que os princípios são o limitado, o ilimitado e a harmonia, como faz Filolau no fr. 1? Além disso, outro problema surge quando Aristóteles, na Metafísica, noticia a doutrina pitagórica dos números de quatro formas:

(1) as coisas são números (A 6, 987b28).

(2) as coisas são constituídas de números (N 3, 1090a20). 987b11).

(3) as coisas imitam ou representam números (A 6,

(4) os elementos dos números são os elementos das coisas (A 5, 985b32).

Não pretendemos aqui expor todas as interpretações sobre um assunto tão polêmico, até porque antes teríamos que ingressar no debate acerca da validade dos relatos de Aristóteles sobre os pitagóricos, o que prolongaria muito este trabalho. Porém, aceitando com reservas os relatos de Aristóteles, apresentaremos uma interpretação que nos parece satisfatória. 0 problema se dá em torno da questão do papel epistemológico ou cosmológico do número.

Parece-nos que Guthrie, seguindo os relatos de Aristóteles, apresenta uma solução satisfatória para esta questão ao argumentar que dizer que uma coisa é número, é também dizer que é constituída de número ou é o elemento do número. Se um objeto $x$ é constituído de $y$, e se podemos analisar os elementos de $y$, portanto os elementos de $y$ também serão os elementos de $x$. Ainda seguindo seu raciocínio, se por exemplo uma estátua é feita de bronze, e o bronze é constituído de cobre e estanho, podemos afirmar que os elementos da estátua são tanto o bronze, assim como o cobre e o estanho, os quais são os elementos do bronze. No que se refere à afirmação de que as coisas imitam ou representam os números, Guthrie defende que a palavra mimesis significava tanto atuação como imitação. A relação de um ator com o seu papel numa peça teatral, para um grego, não era apenas de imitação: um ator não só imitava seu papel, mas era possuído pelo papel. 0 mesmo ocorria nos rituais religiosos dionisíacos quando uma pessoa era tomada pelo deus Dionísio. Naquele momento ela não só agia como Dionísio, ela era o próprio deus. 0 que Guthrie está 
querendo demonstrar é que não havia tanta diferença entre ser e imitar para os Gregos, principalmente para os pensadores pré-socráticos. Desta forma, a afirmação aristotélica de que as coisas imitam os números, não está em contradição com a afirmação de que as coisas são números (GUTHRIE, 2003, p. 229-82).

0 segundo fragmento de Filolau, em que aparece a palavra arithmos, é o fr. 5 que diz:

De fato, o número tem duas espécies que lhe são peculiares, a ímpar e a par, e uma terceira, derivada da combinação destas duas, a par-ímpar. Cada uma das duas espécies tem muitas formas, que cada coisa em si mesma revela. (Estobeu, Anth. I, 21, 7c. In: KIRK; RAVEN; SCHOFIELD, 2008, p. 344)

Neste fragmento encontramos, pela primeira vez, as palavras ímpar (peritton) e par (artion), que também geram uma série de interpretações quando comparamos este fragmento com os relatos de Aristóteles, na Metafísica. Segundo 258 Aristóteles:

Em seguida eles afirmam como elementos constitutivos do número o par e o ímpar; dos quais o primeiro é ilimitado e o segundo limitado. O Um deriva desses dois elementos, porque é par e ímpar ao mesmo tempo. Do Um procede, depois, o número; e os números, como dissemos, constituiriam a totalidade do universo. (Met. A 5, 986a17)

Aristóteles relaciona o par com o ilimitado e o ímpar com o limitado, sendo que o Um é par e ímpar ao mesmo tempo. Uma explicação melhor para esta associação aparece na Física, quando Aristóteles descreve uma prática recorrente entre os pitagóricos de representar os números através de um agrupamento de unidades utilizando bolinhas. Eles acrescentavam marcas ou traços na forma de um gnomon ou ângulo de carpinteiro (ângulo reto) gerando figuras geométricas:

Os Pitagóricos dizem que o ilimitado é o par. É que este, dizem eles, quando está envolvido e limitado pelo ímpar, fornece o elemento ilimitado das coisas existentes. Uma indicação disso é o que acontece com os números. Se os gnomon são colocados ao redor do um, e sem o um, num caso a figura produzida varia continuamente, no outro é sempre a 
mesma. (Fís. T 4, 203a10. In: KIRK; RAVEN; SCHOFIELD, 2008, p. 354)

Quando a série dos números ímpares era colocada ao redor de uma unidade na forma de gnomon, o resultado era sempre uma figura quadrada, portanto permanece sempre sendo a "mesma". Quando a série de números pares era colocada da mesma maneira, a relação entre os lados das figuras geradas (retângulos) era sempre diferente. Conforme a figura:

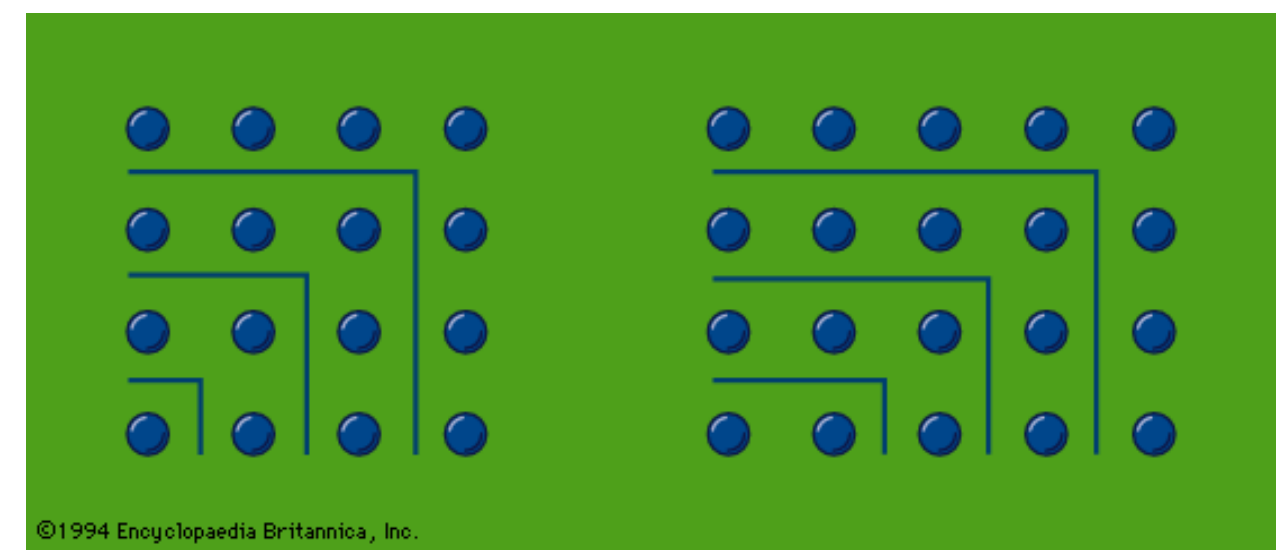

Figura 1: Gnomon ou ângulo de carpinteiro, Fonte: Encyclopaedia Britannica. ${ }^{3}$

W. Burkert, ao analisar o limitado e o ilimitado, afirma que o ímpar era ao mesmo tempo o limitado, enquanto o par era ao mesmo tempo o ilimitado. A partir destes dois princípios, limitado-ímpar e ilimitado-par, "nasce" o Um, e deste os números. Segundo Burkert: "Sem a menor dúvida, pelos relatos de Aristóteles (...) os números ímpares são perainonta e os pares, apeira. 0 artioperitton, feito da mistura dos dois é (...) o Um" (BURKERT, 1972, p. 264). Seguindo seu raciocínio, algo é ilimitado devido a um processo de divisão que não tem fim, e, para algo ser divisível, o que está sendo dividido deve possuir um "espaço vazio no meio", por isso a associação do par com o ilimitado.

3 Disponível em: https://global.britannica.com/topic/gnomongeometry; Acesso em 12 dez. 2016. 
Isto ocorre porque ao dividir um número par, sempre "fica um espaço" entre as unidades, por exemplo: se colocarmos quatro pedras (quatro unidades) sobre uma mesa e dividi-las em partes iguais, teremos duas pedras de um lado e duas pedras do outro, formando um "espaço vazio" entre elas. Já se colocarmos três pedras sobre uma mesa e tentarmos dividi-las em partes iguais, uma das pedras sempre impedirá a divisão, já que não poderá ficar nem de um lado, nem de outro, sem alterar a divisão em partes iguais. Neste caso não há a possibilidade de dividir uma pedra ao meio porque a unidade representa o Uno, que é indivisível. Portanto, ao dividir um número ímpar, uma unidade sempre se colocará como um obstáculo à divisão, e devido a isso se dá a associação do ímpar com o limitado (BURKERT, 1972, p. 258-9).

\section{A Estrutura Musical do Cosmos de Filolau}

Antes de apresentarmos o fr. 6a de Filolau, que trata especificamente da estrutura matemático-musical do cosmos, devemos esclarecer algumas questões preliminares que estão implícitas nesse fragmento.

Se é a harmonia que une e ordena perfeitamente o cosmos através de uma estrutura numérica, então os números e suas razões fornecem a chave para explicar o que é tal ordem harmônica da natureza. Segundo relato de Aristóteles, os pitagóricos dizem que: “(...) como o número dez parece ser perfeito e parece compreender em si toda a realidade dos números, eles afirmavam que os corpos que se movem no céu também deviam ser dez (...)"(Met. A5, 986a8). 0 filósofo está se referindo à tetractys, símbolo pitagórico formado por dez pontos arranjados no formato de um triângulo, sendo a base formada por quatro pontos, a segunda por três, a terceira por dois e a ponta por um ponto, representando, portanto, a soma dos quatro primeiros números inteiros cujo resultado é dez (1 $+2+3+4=10$ ), número extremamente importante para os pitagóricos. 


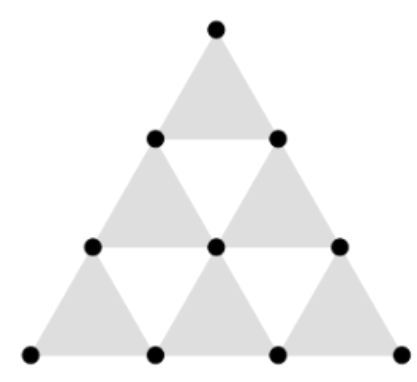

Figura 2: Tetractys. ${ }^{4}$

Além do resultado da somatória de todos os pontos da tetractys ser dez, também observamos na figura dez triângulos: nove pequenos e um grande que representa a totalidade da figura.

A Década, que é o resultado da soma dos quatro primeiros números inteiros, além de ter servido de base para o sistema numérico do Ocidente, representa o princípio de renovação cíclica, uma vez que depois do dez recomeçamos a contagem $(11=10+1,12=10+2$, etc $)$. Os pitagóricos, além de reconhecerem neste símbolo a ordem do cosmos, também reconheciam as faculdades humanas, os princípios para a formação das figuras geométricas, as consonâncias musicais e até conhecimentos esotéricos relacionados aos números e suas simbologias.

Sexto Empírico, acompanhando o relato de Aristóteles na Metafísica (N 3, 1090b5), nos diz que o número um (1) corresponde ao ponto, o dois (2) à linha, o três (3) à superfície (sendo o triângulo o plano mais simples) e o quatro (4) ao sólido (tetraedro, o mais simples dos poliedros regulares). Ainda segundo Sexto, a linha só se torna linha devido a um contínuo movimento do ponto, o plano devido ao movimento da linha e o sólido devido ao movimento do plano (BURKERT, 1972 , p. 66). Os quatro primeiros números também estão associados às quatro faculdades cognitivas, segundo classificação de Aécio: 1 - mente ou inteligência (nous), 2 conhecimento (episteme), 3 - opinião (doxa) e 4 - sensação (aisthesis) (BURKERT, 1972, p. 70).

4 Disponível em:https://pt.wikipedia.org/wiki/Ficheiro:Tetractys.svg;. Acesso em: 12 dez. 2016. 
De acordo com a tradição tardia, sendo a primeira referência encontrada no fr. 9 de Xenócrates recolhido por Porfírio, as relações entre os números, suas razões e os intervalos musicais $(2: 1,3: 2,4: 3)$ teriam sido provadas por Pitágoras:

Heráclides escreve sobre essas coisas em sua Introdução à Música: 'Pitágoras, como diz Xenócrates, descobriu também que os intervalos na música não vêm a ser separados dos números; pois eles são uma inter-relação de quantidade e qualidade. Então, ele investigou sob quais condições surgem intervalos concordantes, discordantes e tudo que seja bem ou mal afinado'. (PORFÍRIO. Comm. 30. 1-5. In: BARKER, 1989, p. 30).

Não podemos ter certeza se realmente Pitágoras foi o responsável pela "descoberta" das razões musicais, já que é bem provável que investigações desse tipo tenham sido realizadas por gregos não pitagóricos, mas que este era um tema importante para os pitagóricos, não resta dúvidas. Uma estória sobre as investigações de Pitágoras acerca dos intervalos musicais refere-se à utilização de um monocórdio, que consistia de uma corda esticada, presa nas suas extremidades e com uma ponte móvel que permitia encurtar ou aumentar o comprimento da corda. Como só possuímos referências explícitas ao monocórdio no Sectio canonis atribuído a Euclides (final do séc. IV a.C.), também não podemos ligar Pitágoras às investigações referentes aos intervalos musicais, por mais que este as tenha realizado. Independentemente do fato de Pitágoras ter realizado ou não tais experimentos, sabemos que os pitagóricos chegaram a conclusões entre números (arithmoi), razões (logoi) e intervalos (diasthemata) que são expostas no modo como eles leem a harmonia cósmica.

No experimento com o monocórdio, vamos supor que a nota emitida pela corda fosse a nota dó que chamaremos de 1 . Se a ponte é posicionada exatamente no meio da corda dividindo-a em duas partes iguais (1:2) e vibrarmos esta corda, temos novamente a nota dó só que uma oitava acima. Chamaremos esse dó mais agudo de 2. É importante notar que a divisão da corda (1:2) e a nota gerada pela divisão (2) são inversamente proporcionais. Quando dividimos a corda em três 
partes iguais (1:3) temos a nota sol que chamaremos de 3. Ao dividir em quatro partes iguais (1:4) temos novamente a nota dó só que duas oitavas acima do primeiro dó e a chamaremos de 4. Poderíamos continuar esse processo, mas não há necessidade para nossa investigação. Essa explicação é necessária porque a matemática pitagórica trabalhava com a teoria das razões que é a relação entre duas quantidades e com a teoria das proporções que é a relação entre duas ou mais razões.

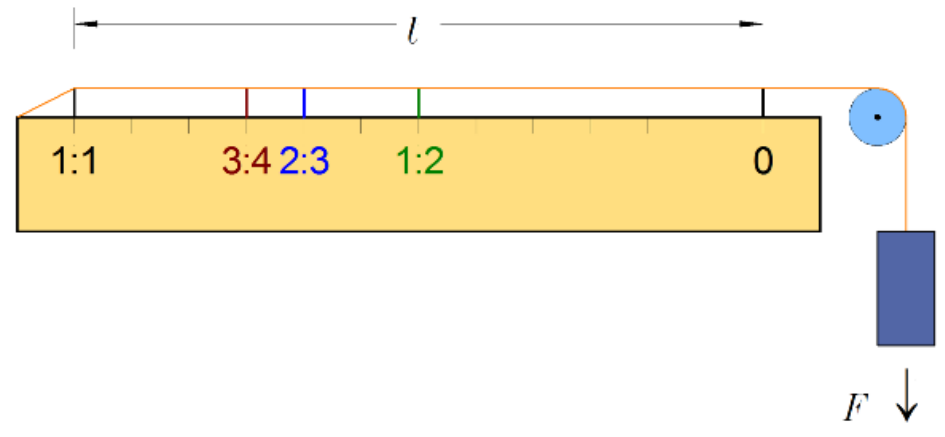

Figura 3: Monocórdio. ${ }^{5}$

A teoria pitagórica das proporções, segundo Nicômaco de Gerasa no Manual de Harmônicos, trabalha com duas médias: a aritmética e a harmônica. Essas médias foram descritas por Arquitas e utilizadas por Platão no Timeu para construir a Alma do Mundo, mas mostraremos pelo fr. 6a que Filolau já tinha conhecimento dessas médias. Segundo Arquitas no fr. 2, recolhido por Porfírio, a definição da média aritmética é a seguinte:

A média é aritmética toda vez que três termos estão em proporção excedendo um ao outro da seguinte forma: pelo que o primeiro excede o segundo, o segundo excede o terceiro. E, nesta proporção, ocorre que o intervalo dos maiores termos é menor e, o dos menores, maior. (Porfírio, On Ptolemy's Harmonics, 1.5. In: HUFFMAN, 2005, p.163)

\footnotetext{
${ }^{5}$ Disponível em:

https://de.wikipedia.org/wiki/Monochord\#/media/File:Monochord.p ng;. Acesso em: 12 dez. 2016.
} 
A fórmula da média aritmética é $\mathbf{x}=(\mathbf{a}+\mathbf{b}): \mathbf{2}$. Portanto, se quiséssemos achar a média aritmética de 12 e 6 faríamos o seguinte cálculo: $\mathrm{x}=(12+6): 2=9$. Nesta média o 9 ultrapassa um extremo e é ultrapassado pelo outro extremo pelo número 3. Portanto $12>9>6$, sendo $9+3=12$ e $9-3=6$.

Se a razão de 2:1 é o intervalo de uma oitava, supondo que 1 é dó e 2 é dó uma oitava acima, qual seria a média aritmética de 2 e 1 ? Ao aplicarmos esta média com o número 1 (nota da corda solta do monocórdio) e com o número 2 (nota gerada pela divisão da corda em duas partes iguais) teremos o seguinte: $\mathbf{x}=(\mathbf{2}+\mathbf{1}): \mathbf{2}=\mathbf{3}: \mathbf{2}$. A razão de $3: 2$ equivale ao intervalo de quinta justa, ou seja, de dó a sol. Quando dividimos a corda em três partes iguais chamamos a nota sol de 3, e como 2 é dó obtemos assim o intervalo entre dó e sol, portanto a quinta justa. É importante ressaltar que neste trabalho as razões serão dadas sempre em termos de frequências vibracionais ao invés de comprimentos de corda. Quando utilizamos a razão 1:2 estamos nos referindo à divisão física da corda, portanto da relação entre comprimentos de corda. Quando utilizamos 2:1 estamos nos referindo ao intervalo musical de uma oitava, portanto da relação entre duas frequências, ou seja, da relação, por exemplo, entre um dó agudo e um dó grave. As duas razões são inversamente proporcionais.

Já a definição da média harmônica, ainda segundo Arquitas é:

A média é subcontrária, o que chamamos de harmônica, toda vez que eles [os termos] são tais que, pela parte de si mesmo que o primeiro termo excede o segundo, por esta parte do terceiro o do meio excede o terceiro. Ocorre que, nesta proporção, o intervalo dos maiores termos é maior e o dos menores é menor. (Porfírio, On Ptolemy's Harmonics, 1.5. In: HUFFMAN, 2005, p.163)

A fórmula da média harmônica é $\mathbf{x}=\mathbf{2}(\mathbf{a} \cdot \mathbf{b}):(\mathbf{a}+\mathbf{b})$. Portanto se quiséssemos achar a média harmônica de 12 e 6 faríamos o seguinte cálculo: $\mathrm{x}=2(12 \cdot 6):(12+6)=8$. Nesta média o 8 ultrapassa um extremo e é ultrapassado pelo outro extremo pela fração 1:3. Como $1: 3$ de 12 é 4 e 1:3 de 6 é 2 , portanto $12>8>6$, sendo $6+2=8$ e $8+4=12$. 
Assim, se a razão de 2:1 é o intervalo de uma oitava, para obter a média harmônica de 2 e 1 teríamos o seguinte cálculo: $\mathbf{x}=\mathbf{2}(\mathbf{2} \cdot \mathbf{1}):(\mathbf{2}+\mathbf{1})=\mathbf{4}: \mathbf{3}$. Já razão de $4: 3$ equivale ao intervalo de quarta justa, ou seja, de sol ao dó mais agudo. Quando dividimos a corda em quatro partes chamamos a nota dó de 4 e quando dividimos em três chamamos a nota sol de 3 , portanto entre sol e dó (mais agudo) temos o intervalo de quarta.

Notemos que todos os intervalos que geramos possuem os números da tetractys, oitava (2:1), quinta (3:2) e quarta (4:3). Não só os números como as próprias razões estão contidas na figura da tetracys, se estabelecermos razões da base do triângulo para cima (4:3:2:1). Estas razões expressam a ordem cosmológica que corresponde às consonâncias perfeitas demonstradas empiricamente quando dividimos o comprimento de uma corda e aplicamos as médias, aritmética e harmônica, no intervalo de oitava justa (2:1).

Agora que esclarecemos as questões matemáticomusicais relacionadas à tetractys, podemos analisar mais detalhadamente o fr. 6a de Filolau:

A magnitude da harmonia é uma quarta (syllaba) e uma quinta (di' oxeian). A quinta é maior que a quarta pela razão 9:8. Pois, da hypate até a mese há uma quarta, e da mese até a neate, uma quinta, mas da neate até a trite, uma quarta, e da trite até a hypate, uma quinta. Aquilo que se encontra entre a trite e a mese é a razão 9:8, a quarta tem a razão 4:3, a quinta 3:2, e a oitava (dia pason) 2:1. Por isso, a harmonia são cinco razões de 9:8 e duas diesis. A quinta são três razões de 9:8 e uma diesis, e a quarta duas razões 9:8 e uma diesis. (Estobeu, Anth. 1.21.7d. In HUFFMAN, 2006, p. 146-7) ${ }^{6}$

Este fragmento apresenta a harmonia, princípio de união cósmica e estrutura matemático-musical que une limitado e ilimitado para a formação do cosmos, cuja estrutura segue a mesma estrutura da escala diatônica, uma vez que a música para os pitagóricos era um microcosmos, ou seja, uma imitação do cosmos.

${ }^{6}$ Trad. de C. Huffman com poucas alterações nossas. 
O primeiro problema que encontramos ao analisar este fragmento é que a terminologia utilizada por Filolau é diferente da terminologia musical típica utilizada pelos gregos. 0 intervalo de quarta era chamado pelos gregos de diatessaron que significava "através de quatro", o de quinta de diapente ou "através de cinco" e o de oitava era chamado de diapason ou "através de todas". Isso se dava porque estes intervalos eram produzidos, respectivamente, tocando a primeira e a quarta nota, a primeira e a quinta, e, por último, a primeira e a última nota. Ao invés desta terminologia, Filolau utiliza syllaba (intervalo de quarta), dioxeion (intervalo de quinta) e harmonia (intervalo de oitava). Esses termos são mais antigos, porém comuns entre os pitagóricos, segundo testemunho de Teofrasto:

Os Pitagóricos costumavam chamar a consonância "através de quatro" [i.e. a quarta] de syllable, a consonância "através de cinco" [i.e. a quinta] de dioxeion, e a consonância "através de todas" [i.e. a oitava], que se referia à escala, eles denominavam harmonia, como também disse Teofrasto. (Eliano, ap. Por. In Ptol. 96.21ff. In: HUFFMAN, 2006, p. 151)

De acordo com Barker, na terminologia musical a palavra harmonia significava, primeiramente, "afinação" ou "padrões de afinação no âmbito de uma oitava" (BARKER, 1989 , p. 14). Ao invés de diapason ("através de todas" ou intervalo de oitava), termo utilizado por Filolau, o uso de harmonia para o intervalo $2: 1$ pode ter sido usado por pitagóricos do séc. V e IV a.C., uma vez que as "afinações" eram comumente pensadas dentro do âmbito de uma oitava. Ainda sobre a terminologia utilizada para os intervalos, encontramos em Filolau o termo diesis (intervalo de semitom), enquanto o mais comum era chamá-lo de leimma ("sobra"). 0 intervalo de semitom era chamado de "sobra" porque era o resultado da subtração de dois tons do intervalo de quarta (como o intervalo de quarta equivale a dois tons e um semitom, ao subtrair dois tons "sobra" um semitom).

Para compreendermos o fragmento de Filolau em sua totalidade, teremos antes que expor alguns fundamentos da teoria musical grega. As escalas gregas mais básicas eram formadas por "duas quartas" ou dois tetracordes, que significa 
"quatro cordas". Esses tetracordes eram combinados de duas maneiras:

1) Synemmenon: que significa "unido", "ligado" ou "encaixado" porque a última nota do primeiro tetracorde é a primeira do segundo tetracorde, gerando, por exemplo, esta escala musical:

\section{Mi Fá Sol Lá}

\section{Lá Si (bemol) Dó Ré}

2) Diezeugmenon: que significa "disjunto", "separado" ou "desunido" porque os dois tetracordes não compartilham uma nota em comum e há um tom entre a última nota do primeiro tetracorde e a primeira nota do segundo tetracorde. A escala musical ficaria desta maneira:

\section{Mi Fá Sol Lá (tom) Si Dó Ré Mi}

Podemos notar que os tetracordes combinados desta última maneira (diezeugmenon) estão dentro do âmbito de uma oitava já que a escala começa e termina em mi. Porém, quando são combinados da primeira maneira (synemmenon), temos uma escala de sete notas e fica faltando uma nota para completar a oitava. Os gregos deram nomes para cada nota desses pares de tetracordes. A nota com maior altura, portanto a nota mais aguda, era chamada de nete que, curiosamente, significava "mais baixa". Isso se dá porque o termo nete está relacionado não com a altura da nota, mas com a posição da mão ao tocar a lira. A nota com menor altura, portanto a mais grave, era chamada de hypate que significa "mais alta", também devido ao posicionamento da mão ao tocar a lira e não devido à altura.

No synemmenon a nota mais aguda do primeiro tetracorde que, neste caso, corresponde à nota mais grave do segundo tetracorde, era chamada de mese ou "meio". No caso dos tetracordes unidos diezeugmenon a nota mais grave do segundo tetracorde era chamada de paramese ou "próxima do meio". Esses dois tetracordes eram depois preenchidos com duas notas que variavam de acordo com os três tipos de gêneros utilizados pelos gregos: diatônico, enarmônico ou cromático. Em Filolau só nos interessa o gênero diatônico que é 
quando os tetracordes são formados por dois tons e a "sobra" ou semitom; diatonos significa que esta escala foi construída "de tom em tom", ou seja, dia tonoi (BARKER, 1989, p. 11-3). Independentemente do gênero utilizado, os nomes das notas dados pelos gregos não mudavam apesar das mudanças de altura. A segunda nota do primeiro tetracorde, portanto a segunda mais grave, era chamada de parhypate ou "próxima da mais baixa" e a nota que vinha logo em seguida era chamada de lichanos ou "dedo indicador". Já no segundo tetracorde, a segunda nota mais aguda era chamada de paranete ou "próxima da mais alta" e a nota logo abaixo era chamada de trite ou "terceira". Portanto, adotando o gênero diatônico, as notas da escala, da mais grave para a mais aguda, com seus respectivos nomes ficariam assim:

\section{1) Synemmenon}

Hypate (Mi), Parhypate (Fá), Lichanos (Sol), Mese (Lá), Trite (Si bemol), Paranete (Dó), Nete (Ré). ${ }^{7}$

\section{2) Diezeugmenon}

Hypate (Mi), Parhypate (Fá), Lichanos (Sol), Mese (Lá), Paramese (Si), Trite (Dó), Paranete (Ré), Nete (Mi).

Dito isso, voltemos ao fragmento de Filolau. Apesar de Estobeu apresentar o fr. 6a como se fosse uma continuação do fr. 6, em Nicômaco esta relação não ocorre. Ele apresenta o fr. 6a em seu Enchiridion, breve tratado sobre os princípios básicos da teoria dos harmônicos, como sendo as conquistas do próprio Pitágoras neste campo (HUFFMAN, 2006, p. 156). O motivo para muitos intérpretes apresentarem esses dois fragmentos como uma continuação se dá por ambos possuírem a harmonia como seu ponto central. Se no fr. 6 temos a harmonia apresentada como um terceiro princípio, que "une" limitado e ilimitado, no fr. 6a Filolau especifica como se dá tal harmonia. Ao lermos os dois fragmentos de uma só vez, pode parecer um salto grande e até mesmo estranho o aparecimento

\footnotetext{
${ }^{7}$ Neste caso não temos a paramese porque possuímos uma nota a menos devido aos dois tetracordes compartilharem uma nota em comum, a mese.
} 
de uma estrutura matemática com terminologia musical, o que fez com que alguns estudiosos duvidassem da conexão entre os dois fragmentos (HUFFMAN, 2006, p. 158-60). Mas de acordo com as informações dadas por Aristóteles na Metafísica, podemos concluir que tal salto não só deixa de ser estranho, como torna-se uma consequência natural de acordo com aquilo que sabemos sobre o pitagorismo antigo. No primeiro livro da Metafísica, Aristóteles diz:

(...) e além disso, por verem que as notas e os acordes musicais consistiam em números; e, finalmente, porque todas as outras coisas em toda a realidade lhes pareciam feitas à imagem dos números e porque os números tinham a primazia na totalidade da realidade, pensaram que os elementos dos números eram elementos de todas as coisas, e que a totalidade do céu era harmonia e número. Eles recolhiam e sistematizavam todas as concordâncias que conseguiam mostrar entre os números e os acordes musicais, os fenômenos, as partes do céu e todo o ordenamento do universo. (Met. A 5, 985b32)

Aristóteles afirma que a totalidade do céu é harmonia e número, e que os pitagóricos recolhiam e sistematizavam as relações entre os números, os acordes musicais, os fenômenos, as partes do céu e todo o ordenamento do universo. Desta forma, a conexão entre os fragmentos 6 e $6 a$ não só é necessária como contêm o ponto central, e talvez o legado mais importante de toda a investigação filosófica daquilo que entendemos por pitagorismo, que servirá de base teórica para a doutrina da Harmonia das Esferas: que o cosmos é formado por uma harmonia, entendida como terceiro princípio cosmológico, que une limitantes e ilimitados através de uma estrutura matemático-musical específica.

Analisaremos agora o fr. 6a em partes.

1) "A magnitude da harmonia é uma quarta (syllaba) $e$ uma quinta (di' oxeian). A quinta é maior que a quarta pela razão 9:8".

Filolau nos diz que a harmonia consiste de um intervalo de quinta e um de quarta, e que a quinta é maior do que a quarta pela razão 9:8. Ora, se a quinta justa é 3:2 e a 
quarta justa $4: 3$, se somarmos ${ }^{8}$ os dois intervalos já podemos deduzir o "tamanho" da harmonia. Se $(3: 2) \cdot(4: 3)=2: 1$, portanto a magnitude da harmonia consiste em uma oitava ou $2: 1$. Para confirmarmos se a quinta é realmente maior que a quarta pela razão 9:8, basta subtrair 4:3 de 3:2. Dessa forma temos $(3: 2):(4: 3)=9: 8$. É fundamental estabelecer a diferença entre a magnitude da harmonia e o que ela é. Ela não é 2:1, mas sua magnitude é de uma oitava ou 2:1. Já a estrutura matemática dentro do âmbito de uma oitava é a harmonia que une, ou combina, limitantes e ilimitados. É difícil traduzirmos a palavra harmonia num contexto musical, porém podemos compreender harmonia como "escala" (BURKERT, 1972, p. 390), assim como "afinação dentro de uma oitava" (BARKER, 1989, p. 37). As duas traduções sugerem que a harmonia não é uma oitava (2:1), mas uma estrutura matemática dentro do âmbito de uma oitava. 0 próprio Filolau, um pouco mais adiante no fr. 6a, quando especifica as razões matemáticas que correspondem aos intervalos musicais, utiliza dia pason 270 referindo-se ao intervalo de oitava, mas não à harmonia. 0 começo do fragmento também nos mostra que Filolau tinha conhecimento das médias, harmônica e aritmética, antes atribuídas a Arquitas, já que afirma que a magnitude da harmonia (2:1) é uma quinta (3:2) e uma quarta (4:3). Como vimos, essas razões possuem os números da tetractys cuja soma é dez.

2) "Pois, da hypate até a mese há uma quarta, e da mese até a neate, uma quinta, mas da neate até a trite, uma quarta, e da trite até a hypate, uma quinta".

Se da hypate até a mese temos um intervalo de quarta, isso significa que entre a nota mais grave e a nota mais aguda do primeiro tetracorde temos a razão 4:3. Já entre a mese e a

${ }^{8}$ Quando trabalhamos com razões, somar intervalos resulta em multiplicação, já subtrair intervalos resulta em divisão. Também é fundamental notar que na teoria musical pitagórica não havia a ideia de irracionalidade na matemática. Para os pitagóricos era impossível dividir uma oitava, quinta ou quarta. Portanto, na teoria das proporções musicais, 3:2 nunca seria igual a 1,5. Na realidade não existe 1,5 (BURKERT, 1972, p. 369-370). 
neate, ou seja, entre a última nota do primeiro tetracorde e a mais aguda do segundo tetracorde temos a razão 3:2, que quando somadas essas razões, como sabemos, resultam no intervalo de oitava (2:1). Depois disso, Filolau faz o caminho contrário, ou seja, ao invés de "medir" a distância da nota mais grave até a mais aguda, ele começa da nota mais aguda e chega até a mais grave. Neste momento do fragmento surge um problema: Filolau diz que entre a neate e a "terceira corda", ou trite, temos um intervalo de quarta (4:3), mas ao fazermos as contas da distância entre a neate e a trite, tanto nos tetracordes combinados diezeugmenon como nos synemmenon, não encontramos um intervalo de quarta, mas um de terça. Nicômaco, logo após apresentar o fragmento, percebe esse problema e fornece duas explicações:

Por Trite ele quer dizer Paramese no heptacorde, antes da inserção da nota divisora no octacorde. (1) Isso [i.e. Trite = Paramese] foi separado da Paranete (d) por um intervalo indivisível de um tom e meio. A corda inserida tomou um tom inteiro deste, e o semitom restante foi deixado no diezeugmenon entre a Paramese e a Trite. Compreensivelmente, a antiga Trite foi separada por uma quarta da Nete (b-e), intervalo que agora é encerrado pela Paramese (b) ao invés da outra... (2) Outros dizem, persuasivamente, que a nota inserida não se encontrava entre a Mese e a Trite, mas entre Trite e Paranete, e o que agora era chamado de Trite, enquanto a antiga Trite tornouse Paramese no diezeugmenon. (Nicômaco. Ench. 9, p. 253.4ff. In: BURKERT, W. Op. cit. p. 392)

Nestas explicações, Nicômaco está pensando tanto na escala de sete notas (synemmenon) como na de oito notas (diezeugmenon) dentro do âmbito de uma oitava, ao contrário da utilização usual dos gregos em que a combinação synemmenon dos tetracordes ficaria faltando uma nota para completar uma oitava (BURKERT, 1972, p. 393). Ainda de acordo com Nicômaco, quando Filolau usa o termo trite, na realidade está se referindo ao que entendemos anteriormente por paramese (si). E como em Filolau, segundo a teoria de Burkert, o heptacorde (synemmenon) compreende uma oitava, a distância entre trite (= paramese) e paranete (ré) é de um tom e meio (entre si e ré temos um tom e um semitom de distância). 
Assim, o segundo tetracorde da escala de sete notas de Filolau só possuí três notas ao invés de quatro. Por exemplo:

Filolau

a) Segundo tetracorde da escala de sete notas de

\section{Trite (tom + semitom) Paranete (tom) Nete}

Ora, se somarmos a distância entre trite e nete no ex. a, temos exatamente dois tons e um semitom, ou seja, um intervalo de quarta (4:3). Portanto Filolau está certo ao dizer que entre a nete (nota mais aguda) e a trite (aqui entendida como a "terceira corda" a partir da nete) há um intervalo de quarta. A teoria de Burkert é muito consistente não apenas pelos indícios já encontrados nas explicações de Nicômaco, mas devido ao fato de no começo do fr. 6a, Filolau afirmar que a magnitude da harmonia é a soma de uma quinta e uma quarta, que resulta numa oitava. Seguindo este raciocínio, não faria sentido uma escala, mesmo que de sete notas, que não completasse uma oitava.

Logo depois, Nicômaco, ao explicar a transição entre a escala de sete notas para a de oito, diz que a corda (ou nota) que foi inserida para formar a escala de oito notas (diezeugmenon) "tomou" um tom da distância de um tom e meio entre a antiga trite e a paranete. Desta forma, no diezeugmenon, o semitom que "sobrou" se encontra entre a paramese e a trite, como vemos no ex. b:

b) Segundo tetracorde da escala de oito notas (diezeugmenon)

\section{Paramese (semitom) Trite (tom) Paranete (tom) Nete}

Ao analisarmos a segunda explicação de Nicômaco, ficamos ainda mais confusos do que com a primeira. Depois do que explicamos acima, é natural pensarmos que a nova nota para formar a escala de oito notas foi inserida entre a antiga trite (= paramese) e a paranete. Mas Nicômaco, ao dar sua segunda explicação, afirma que "outros" dizem que a nova nota não foi inserida entre mese e trite, mas entre trite e paranete, sugerindo, em sua primeira explicação, que a nota inserida se encontrava entre mese e trite. Se no primeiro caso seguimos a interpretação de Burkert, agora seguiremos a de Barker. 
Segundo Barker, Nicômaco realmente afirma que a nova nota inserida se encontrava entre mese e trite, fazendo com que a antiga trite fosse elevada em um semitom. Nesta escala, a antiga trite continua sendo trite, mas um semitom acima. Não se trata, portanto, de uma mudança de nome, mas de uma mudança de posição da trite na escala synemmenon para a diezeugmenon. Desta forma, a nova nota inserida seria a paramese, mas assumindo a posição da antiga trite (BARKER, 1989, p. 255). 0 resultado das duas explicações de Nicômaco é o mesmo, como vimos no ex. b, só a forma de explicar a transição da escala de sete notas para a de oito é que difere.

[Mese] (tom) Paramese (semitom) Trite (tom) Paranete (tom) Nete

3) "Aquilo que se encontra entre a trite e a mese é a razão 9:8, a quarta tem a razão 4:3, a quinta 3:2, e a oitava (dia pason) 2:1".

Agora que sabemos que Filolau se refere a uma escala de sete notas, mas que está no âmbito de uma oitava, "aquilo que está" (distância) entre a "terceira corda" (trite) e a "corda do meio" (mese) é a razão 9:8. Se calcularmos o intervalo de um tom pela diferença entre uma quinta (3:2) e uma quarta (4:3), o que Filolau chama de 9:8, a distância entre a antiga trite (si) utilizada por Filolau e a mese (lá) também é de 9:8 (entre lá e si temos um tom). Da nota mais grave (hypate) até a mese temos uma quarta, enquanto que da mesma hypate até a antiga trite temos uma quinta, por isso 9:8 é a diferença entre a mese e a trite, ou seja, entre uma quarta e uma quinta.

4) "Por isso, a harmonia são cinco razões de 9:8 e duas diesis. A quinta são três razões de 9:8 e uma diesis, e a quarta duas razões 9:8 e uma diesis".

Pela parte final do fragmento, vê-se a estrutura matemático-musical da harmonia, que une limitado e ilimitado para a formação do cosmos. 0 curioso é que só no final do fragmento aparece o termo dieses para os intervalos de semitom. A terminologia comumente utilizada pelos gregos era leimma que significa "sobra", porque ao subtrairmos dois tons de um intervalo de quarta, o restante ou a "sobra" é um semitom. Para calcularmos a razão de um semitom temos primeiro que calcular a de dois tons. Como um tom 
corresponde à razão 9:8, temos $(9: 8) \cdot(9: 8)=81: 64$. Se dois tons, ou o intervalo de terça, corresponde à razão 81:64, basta subtrairmos 81:64 do intervalo de quarta. Desta forma, (4:3) : $(81: 64)=256: 243$, razão que corresponde ao intervalo de um semitom ou diesis. Portanto a estrutura matemática do cosmos de Filolau é a seguinte:

$\begin{array}{lllllll}9: 8 & 9: 8 & 256: 243 & 9: 8 & 9: 8 & 9: 8 & 256: 243\end{array}$

Para obtermos as razões correspondentes aos outros intervalos, no caso a sexta maior e a sétima maior, basta acrescentar um tom (9:8). A razão correspondente ao intervalo de sexta é o resultado da soma de um tom ao intervalo de quinta, portanto $(3: 2) \cdot(9: 8)=27: 16$. Aplicamos o mesmo procedimento para o intervalo de sétima, somamos um tom ao intervalo de sexta, $(27: 16) \cdot(9: 8)=243: 128$.

As razões inseridas no intervalo de oitava (2:1) ficariam assim:

$\begin{array}{llllllll}1 & 9: 8 & 81: 64 & 4: 3 & 3: 2 & 27: 16 & 243: 128 & 2\end{array}$

A partir da análise deste fragmento, podemos observar que todos os intervalos que constituem esta harmonia apresentam uma relação entre artion e peritton. Não há um intervalo que não seja a combinação de um número par com um número ímpar. E como pares e ímpares estão relacionados com ilimitados e limitantes, todos os intervalos musicais que formam a estrutura do cosmos de Filolau possuem limitantes e ilimitados combinados em sua natureza. Esta estrutura, que aparece pela primeira vez no ocidente no pensamento de Filolau e que chegou até nossos dias por meio de fragmentos doxográficos, servirá de base para todas as teorias platônicas e neoplatônicas posteriores, que influenciarão de forma decisiva o pensamento científico e filosófico do ocidente. Na música, a relação entre cosmologia e matemática (ou entre natureza, matemática e sons), permanecerá no pensamento musical 
medieval, como herança da cultura grega, e reaparecerá nas polifonias renascentistas, no contraponto de Bach e nas vanguardas do século XX.

\section{Referências bibliográficas}

ARISTÓTELES. Metafísica. Texto grego com tradução de Giovanni Reale (Trad. para o português de Marcelo Perine). São Paulo: Loyola, 2005.

BARKER, A. Greek Musical Writings I: The Musician and his Art. Cambridge: Cambridge University Press, 2004.

Greek Musical Writings II: Harmonic and Acoustic Theory. Cambridge: Cambridge University Press, 1989.

BURKERT, W. Lore and Science in Ancient Pythagoreanism. (Trad. inglesa de E. L. Minar, Jr. aumentada e revisada pelo próprio autor) Cambridge, Massachusetts: Harvard University Press, 1972.

COMOTTI, G. Music in Greek and Roman Culture. Baltimore: The Johns Hopkins University Press, 1989.

CHRISTENSEN, T. (ed.) The Cambridge History of Western Music Theory. Cambridge: Cambridge University Press, 2002.

GUTHRIE, W. K. C. A History of Greek Philosophy: The earlier Presocratics and the Pythagoreans. Cambridge: Cambridge University Press, 2003.

HENDERSON, Isobel. Ancient Greek Music. In: WELLESZ, Egon (Ed.). The New Oxford History of Music: Ancient and Oriental Music, vol I. Oxford: Oxford University Press, 1957.

HUFFMAN, C. Philolaus of Croton: Pythagorean and Presocratic. Cambridge: Cambridge University Press, 2006.

_. Archytas of Tarentum: Pythagorean, Philosopher and Mathematician King. Cambridge: Cambridge University Press, 2005

KAHN, C. H. Pitágoras e os Pitagóricos: uma breve história. Trad. de Borges, L. C. São Paulo: Loyola, 2007.

__. Pythagorean Philosophy Before Plato. In The Presocratics: A Collection of Critical Essays. Ed. Mourelatos. Garden City, NY: Anchor Press, 1974. Reprint, Princeton: Princeton University Press, 1993.

KIRK, G. S., RAVEN, J. E., SCHOFIELD, M. Os Filósofos Pré-socráticos. Trad. de Fonseca, C. A. L. Lisboa: Fundação Calouste Gulbenkian, 2008. 
LEVIN, F. R. The Harmonics of Nichomachus and the Pythagorean Tradition. Philadelphia: The American Philological Association, 1975.

_. The Manual of Harmonics of Nicomachus the Pythagorean: Translation and Commentary. Michigan: Phanes Press, 1994.

MATHIESEN, T. J. Apollo's Lyre: Greek Music and Music Theory in Antiquity and Middle Ages. Nebraska: University of Nebraska Press, 1999.

. Greek Music Theory. In: CHRISTENSEN, T. (ed.) The Cambridge History of Western Music Theory. Cambridge: Cambridge University Press, 2002.

NOLAN, C. Music Theory and Mathematics. In: CHRISTENSEN, T. (ed.) The Cambridge History of Western Music Theory. Cambridge: Cambridge University Press, 2002.

PLATÃO. A República. Introdução, tradução e notas de Maria Helena da Rocha Pereira. Lisboa: Fundação Calouste Gulbenkian, 2001.

. Timeu. Tradução de Maria José Figueiredo e introdução de José Trindade Dos Santos. Lisboa: Instituto Piaget, 2003.

XENAKIS, I. Formalized Music: Thought and Mathematics in Composition. Revised English edition. Stuyvesant, NY: Pendragon Press, 1992. 